$\$$ Research Square
Preprints are preliminary reports that have not undergone peer review.

They should not be considered conclusive, used to inform clinical practice, or referenced by the media as validated information.

\title{
The Association between Homocysteinemia and Mortality in Pre-dialysis CKD patients: A Propensity-Score Matched Analysis Using NHANES-National Death Index Link
}

\author{
Je Hun Song \\ University of Ulsan College of Medicine
}

\section{Hyuk Huh}

Seoul National University Hospital

\section{Eunjin Bae}

Department of Internal Medicine, College of Medicine, Gyeongsang National University, Jinju

\section{Jeonghwan Lee}

Seoul National University Boramae Medical Center

\section{Jung Pyo Lee}

Seoul National University Boramae Medical Center

\section{Jong Soo Lee}

University of Ulsan College of Medicine

\section{Kyung Don Yoo}

University of Ulsan College of Medicine

Gwang Sil Kim ( $\nabla$ zidan007@paik.ac.kr)

Inje University College of Medicine

\section{Research Article}

Keywords: Chronic kidney disease, cardiovascular disease, Hyperhomocysteinemia, homocysteine, mortality

Posted Date: October 11th, 2021

DOI: https://doi.org/10.21203/rs.3.rs-948936/v1

License: @ (i) This work is licensed under a Creative Commons Attribution 4.0 International License. Read Full License 


\section{Abstract}

Background: Hyperhomocysteinemia (HHcy) is considered a risk factor for cardiovascular disease (CVD) including chronic kidney disease (CKD). In this study, we investigated the association between serum homocysteine (Hcy) level and mortality according to the presence of CKD.

Methods: Our study included data of 9,895 participants from the 1996-2016 National Health and Nutrition Examination Surveys (NHANES). Moreover, linked mortality data were included and classified into four groups according to the Hcy level. Multivariable-adjusted Cox proportional hazards models using propensity-score were used to examine dose-response associations between Hcy level and mortality.

Results: Of 9,895 participants, 1032 (21.2\%) participants were diagnosed with CKD. In a multivariate Cox regression analysis including all participants, Hcy level was associated with all-cause mortality, compared with the $1^{\text {st }}$ quartile in Model 3 ( $2^{\text {nd }}$ quartile: hazard ratio (HR) $1.751,95 \%$ confidence interval $(\mathrm{Cl}) 1.348-2.274, p<0.001 ; 3^{\text {rd }}$ quartile: HR 2.220, $95 \%$ Cl 1.726-2.855, $p<0.001 ; 4^{\text {th }}$ quartile: HR 3.776, 95\% Cl 2.952-4.830, $\left.p<0.001\right)$. In the non-CKD group, there was a significant association with all-cause mortality; however, this finding was not observed in the CKD group. The observed pattern was similar after propensity score matching. In the non-CKD group, overall mortality increased in proportion to Hcy concentration $\left(2^{\text {nd }}\right.$ quartile: HR $2.195,95 \% \mathrm{Cl} 1.299-3.709, p=0.003 ; 3^{\text {rd }}$ quartile: HR $2.607,95 \% \mathrm{Cl} 1.570-4.332, p<0.001 ; 4^{\text {th }}$ quartile: HR $3.720,95 \% \mathrm{Cl} 2.254-6.139, \mathrm{p}<0.001)$. However, the risk of all-cause mortality according to the quartile of Hcy level did not increase in the CKD group

Conclusion: This study found a correlation between the Hcy level and mortality rate only in the non-CKD group. This altered risk factor patterns may be attributed to protein-energy wasting or chronic inflammation status that is accompanied by CKD.

\section{Background}

The prevalence of chronic kidney disease (CKD) increases with age, along with the risk of cardiovascular disease (CVD) [1, 2]. Prior evidence suggest an association between CKD and CVD through various sharing mechanisms; moreover, another study presented an association between CVD and CKD among patients with advanced CKD [3] who were undergoing dialysis and also those with mild to moderate CKD [4]. There are several potential traditional mechanisms through which CKD could lead to CVD. For example, systemic inflammation might lead to uncontrollable levels of uremic metabolite, such as phosphorus, which leads to changes in cardiac remodeling [4].

Prior studies have examined homocysteine (Hcy) as a risk factor for CVD and cerebrovascular disease in the general population [5]. However, there is a lack of research on the risk factor of CVD in CKD patients. Hcy is used as an indicator of vascular disease, especially in Asian populations, who report insufficient daily folic acid intake, compared with that of Western populations [6]. Prior studies considered an increase in Hcy concentration as not being the cause of CKD, but as the result or coincidence of CKD, which was thought to be due to the decrease in glomerular filtration rate $(G F R)[7,8]$. However, recent studies suggest that hyperhomocysteinemia (HHcy) may be a risk factor of CKD itself. The results of a meta-analysis of 41 studies showed that Hcy level was inversely correlated with the decrease in GFR [9]. Moreover, studies on elderly patients with hypertension in China reported that HHcy can predict a decline of kidney function [10]. Furthermore, CVD may also occur in addition to CKD through various mechanisms such as increased Hcy concentration, oxidative stress, and endothelial dysfunction [11]. However, results on the effect of HHcy on death in advanced CKD patients are inconclusive. In particular, reverse epidemiology was observed in the mortality of advanced CKD patients, compared with that of the general population group [12]. Further, this effect was highly associated with the malnutrition-chronic inflammation hypothesis for obesity using body mass index (BMI) $[13,14]$ and dyslipidemia $[15]$ in CKD patients. 
Notably, dialysis patients were associated with low Hcy and mortality [16, 17]. In a HOST-trial in 2007, a randomized trial announced vitamin combination therapy in 2,056 CKD and end-stage renal disease (ESRD) patients. In this trial, while the level of Hcy had a statistically significant decrease, it did not improve CVD outcome [18]. Moreover, as prior research has focused on traditional risk factors such as high blood pressure and Diabetes mellitus (DM), there is limited research on the factors influencing increased CVD risk among CKD patients. Therefore, in this study, we aimed to identify patients with CKD at each stage by using open-source nationwide data, while determining the change in mortality according to the Hcy level among CKD and non-CKD patients.

\section{Materials And Methods}

\section{Study population and ethics statement}

The National Health and Nutrition Examination Surveys (NHANES) is a large cross-sectional survey conducted for citizens of the United States; it provides basic and clinical information related to the prevalence and risk factors of chronic diseases. We used anonymized information of participants included in the NHANES from 1996-2016. This study protocol received approval by the National Center for Health Statistics (NCHS) Institutional Review Board of NHANES [19]. We included 9,895 out of a total of 92,062 participants by excluding those with missing GFR, Hcy level, and mortality data (Fig. 1). The National Center for Health Statistics (NCHS) Research Ethics Review Board (ERB) approved the NHANES protocols (protocol \#98-12, \#2005-06 and \#2011-17, available site https://www.cdc.gov/nchs/nhanes/irba98.htm ) and written informed consent was obtained from NHANES participants, and all procedures were approved by the NCHS Research Ethics Review Board. And this research has been carried out in accordance with the Declaration of Helsinki. The NHANES performance of adult specimens was evaluated based on a method described in another previous study [20].

\section{Measurement of homocysteine and covariates}

Blood samples from NHANES participants are stored, processed, and analyzed according to standardized protocols. Total plasma Hcy were measured in blood samples of participants. The Abbott Homocysteine assay was used to measure Hcy in plasma. This laboratory method is a fully automated fluorescence polarization immunoassay from Abbott Diagnostics. Further, total plasma Hcy concentrations were calculated using a machine-stored calibration curve. In addition, other laboratory data such as serum creatinine, albumin, and uric acid were analyzed. Moreover, self-reports were used to collect information on demographic variables of participants including age, gender, race, education level, and smoking status.

\section{Definitions of variables and outcomes}

CKD was defined as a urine albumin creatinine ratio (UACR) $\geq 30 \mathrm{mg} / \mathrm{g}$ or an estimated glomerular filtration rate (eGFR) < $60 \mathrm{~mL} / \mathrm{min} / 1.73 \mathrm{~m}^{2}$. Hypertension was defined as systolic blood pressure (SBP) $\geq 140 \mathrm{mmHg}$ and/or a diastolic blood pressure $(\mathrm{DBP}) \geq 90 \mathrm{mmHg}$. DM was defined as hemoglobin A1c $\geq 6.5 \%$, self-reports of prior diagnosis of DM, or consumption of medications for DM. The primary outcome of the study was all-cause mortality, which was defined using the National Death Index (NDI) mortality data.

\section{Statistical analysis}

We divided study population into two groups (i.e., CKD and non-CKD group) on the value of eGFR and/or UACR. For group comparisons, t-test and $\chi 2$ test were used for continuous variables and proportions, respectively. Cox regression models were applied to calculate the hazard ratios (HRs). Further, 95\% confidence intervals (Cls) were set for homocysteine and allcause mortality. In Model 3, we included covariates that had a significant association (e.g., age, gender, serum albumin, UACR, smoking status, BMI, concurrent history of hypertension, and DM; P <0.05). We used Kaplan-Meier survival curves to calculate all-cause mortality. Fig. 2 shows the methodology of propensity-score matched analysis. The propensity score and standardized differences were used to compare baseline characteristics between the two groups. The propensity score 
is was used to balance covariates between the two groups to reduce biasing effects of between-group differences in baseline characteristics on measured effects of the CKD. The nearest neighbor matching method and 1:5 matching algorithm without replacement were used to select a match in the control group for each individual in the CKD group (Fig 2).

\section{Results}

\section{Baseline characteristics of the study population}

The average age of the study participants was $47 \pm 20$ years; further, the sample comprised $48.4 \%$ males. Among the study population, $3,771(38.1 / \%)$ had hypertension, whereas 1,117 (11.3\%) had DM. The CKD group was older in age (CKD: $73 \pm$ 11 years; non-CKD: $44 \pm 18$ years, $p<0.001$ ) and had a lower level of education, compared with the non-CKD group. Moreover, in the CKD group, BMI, SBP, DBP, and the prevalence of hypertension and DM were high, whereas serum albumin level was low (Table 1).

\section{Plasma homocysteine level according to the stage of Chronic Kidney Disease}

For total plasma Hcy, the overall mean was $8.8 \pm 4.7 \mathrm{umol} / \mathrm{L}$. Participants in the CKD-group had a higher Hcy level, compared with those in the non-CKD group $(13.5 \pm 5.1$ versus $8.3 \pm 4.3 \mathrm{umol} / \mathrm{L}, p<0.001)$. Although an identical trend from CKD stage 4 to CKD stage 5 was not observed, Hcy levels in the CKD group according to the stage showed a tendency of gradual increase as the stage progressed from stage 1 to stage 4 (Fig. 3a). The same pattern was observed when analyzed separately by gender (Fig. 3b).

\section{Analysis of all-cause mortality according to homocysteine level by quartile}

We divided participants into quartiles according to the Hcy level. In overall population, mortality rate was increased as the level of Hcy increased (Figure 4). We used multivariate Cox regression analysis to adjust for age and gender in Model 2; further, we adjusted for age, gender, serum albumin, UACR, smoking status, BMI, concurrent history of hypertension, and DM in Model 3. In a multivariate Cox regression analysis comprising all participants, Hcy level was associated with allcause mortality, compared with the $1^{\text {st }}$ quartile in Model $3\left(2^{\text {nd }}\right.$ quartile: HR $1.751,95 \% \mathrm{Cl} 1.348-2.274, p<0.001 ; 3^{\text {rd }}$ quartile: HR 2.220, 95\% Cl 1.726-2.855, $p<0.001 ; 4^{\text {th }}$ quartile: HR 3.776, 95\% Cl 2.952-4.830, p<0.001). In the non-CKD group, a significant association with all-cause mortality was observed; however, this was not observed in the CKD group (Table 2).

\section{Association between homocysteine and chronic kidney disease}

Through a multivariate logistic regression analysis, the odd ratios (ORs) of age, hypertension, and DM, which are the conventional risk factors for CKD were 1.096 (1.083-1.109, $p<0.001), 1.699$ (1.259-2.291, $p<0.001)$, and 1.824 (1.264$2.633, p=0.001)$, respectively. However, factors such as obesity and smoking were not significantly correlated. Compared with the $1^{\text {st }}$ quartile of Hcy level, the ORs were $2.439(1.074-5.539, p=0.033)$ and $7.518(3.342-16.911, p<0.001)$ in the $3^{\text {rd }}$ and $4^{\text {th }}$ quartile, respectively. Thus, we observed a significant correlation between the Hcy level and CKD (Table 3).

\section{Analysis before and after propensity score matching}

We performed propensity score matching by dividing the CKD and non-CKD group. Participants were allocated to each group in a 1:5 ratio. We used variables including age, gender, race, BMI, DM, and hypertension for propensity score matching. Baseline characteristics of the study population after propensity score matching are presented in Table 4 . After propensity score matching, we included 2,015 and 741 participants in the non-CKD group and CKD group, respectively. After adjusting for variables, the differences in socioeconomic factors such as race, education level, BMI, and smoking history were offset between the groups. Moreover, we found a decrease in the differences in factors such as the prevalence of DM, hypertension, SBP, and serum uric acid level (Table 4). The risk of mortality according to Hcy level after propensity score 
matching is presented in Table 5. In the multivariate Cox regression analysis, we found similar results compared to those observed in the crude analysis. The risk of all-cause mortality according to the quartile of Hcy level was not found to increase in the CKD group. However, in the non-CKD group, the Hcy level was associated with all-cause mortality (Table 5).

\section{Discussion}

This study analyzed the association between serum Hcy concentration and all-mortality in CKD and non-CKD patients using NHANES data. An increased survival rate was observed in patients with high levels of Hcy in the non-CKD group only. Moreover, we confirmed a significant correlation between the Hcy level and mortality risk; this risk was found to have a similar pattern after adjusting for confounding factors including age, gender, and inflammation or nutrition in the non-CKD group. However, in the CKD group, even in cases where the concentration of homocysteine was high, no association to mortality was observed. Therefore, this is a result consistent with the reverse epidemiology hypothesis of Hcy and mortality in CKD patients [12].

Although, it is well known that patients with CKD have a high CVD risk [21], there is little research on the mechanism through which this risk increases. Therefore, studying and identifying contributing factors other than these accompanying diseases are an important part of improving the prognosis of CKD patients. Further, vascular calcification related to mineral bone disease in CKD patients (medial calcification) [22] and inflammation such as C-reactive protein (CRP) or interleukin and endothelial dysfunction and metabolic disorder associated with adiponectin or FGF-23 are consider early biomarkers and etiologies causing excessive CVD occurrence of CKD [23].

The high prevalence of HHcy in patients with $\operatorname{CKD}[24,25]$ has generated interest in the potential role of total homocysteine (tHcy) as a risk factor for the excess risk of CVD that is evident in this population [26]. In 1969, Macully first announced in a post-mortem case report that HHcy may be associated with atherosclerosis [27], which led to the concept of the "Hcy hypothesis," that considered Hcy a potential risk factor for CVD, contributing to vascular physiology. Since then, observational studies have confirmed the association between HHcy and CVD. In the general population, HHcy is associated with arteriosclerosis, increased CVD risk, and mortality. In addition, even in patients with coronary artery disease [5], it is associated with poor prognosis and is considered a prognostic factor of poor outcome in patients with Type 2 DM [28]. While there have been cumulated hypotheses on the association between CVD occurrence and HHcy, Hcy is known to activate the associated pathway of atherogenesis or thrombosis by endothelial dysfunction, inflammation, and oxidative stress [24, 25, 29]. In addition, studies have reported an association between patients with gene variance and metabolism in Hcy, such as methylenetetrahydrofolate reductase (MTHFR) 677C raise CVD risk with elevated Hcy [23, 26]. Finally, there have also been reports that the administration of folic acid or vitamin B12 can lower the Hcy level and reduce mortality [22, 30]. Owing to this evidence, HHcy has been recognized as a risk factor for CVD occurrence. Although BMI, serum cholesterol, and high blood pressure are traditional risk factors for cardiovascular disease and mortality in the general population, in patients with CKD with regards to Hcy, the results of prior studies reveals the effect of reverse epidemiology in these traditional risk factors [18,31]. Although HCY is known to be increased in CKD patients [32, 33], findings regarding whether it is an independent risk factor for increasing CVD risk in CKD patients are inconclusive [34-37]. In two studies with 367 and 88 hemodialysis patients, respectively, the low Hcy level in ESRD patients was observed to increase CVD outcome $[38,39]$; moreover, Hcy also showed a reverse epidemiology pattern as mentioned above. In addition, the control over risk factors can reversely prove whether the risk factors reduce disease incidence. Since folate and vitamin B12 act as cofactors in Hcy metabolism, insufficiency of these cofactors could cause HHcy [40]. Therefore, there have been several studies on the improvement in CVD outcome after administration of VitB12 and folate for the treatment of HHcy. In contrast, a systematic review and meta-analyses revealed that Hcy-lowering treatment did not improve CVD outcomes in patients with a high level of Hcy among the ESRD population [31, 32].

The results of our study show that HHcy was highly correlated with mortality in the general population; moreover, the effect was maintained consistently when various confounding factors were calibrated. However, in CKD patients, the level of Hcy 
was not found to be associated with mortality before and after propensity matching, indicating a pattern corresponding to the reverse epidemiology.

As mentioned above, in particular, CKD is known as a representative disease in which reverse epidemiology occurs [12]. Several researchers explain this inverse correlation using several mechanisms. First, inflammation and protein-energy wasting (PEW), which occur in advanced CKD patients, have been discussed. In fact, previous studies show that tHcy decreased when CKD patients were accompanied by inflammation or PEW [16, 39, 41, 42]. In addition, prior studies report an association between inflammations, PEW, and poor CVDs $[43,44]$. Similarly, a reduction in albumin and Hcy level was observed in advanced CKD patients in this study. Therefore, PEW can offset the effect of HHcy on the clinical outcome including mobility. The second possible explanation is selection bias, which included survival bias. This is also a pattern that is observed in epidemiology studies among elderly [45] and advanced CKD patients, including ESRD patients. As these patients have high morbidity and mortality, compared to that of the general population, they may be viable targets for cross-section studies. In addition, even among CKD patients, there is an immense difference in epidemiological characteristics between patients who have just begun dialysis and those who have elapsed time [46]. Finally, in describing reverse epidemiology, time discrepancy is a competitive risk factor that can affect mortality. This can be explained first with the obesity paradox, as overweight or obesity is known to be highly related to CVD outcomes in developed countries such as the United States and Europe with high average life expectancy $[47,48]$. Nevertheless, in developing countries, undernutrition is known to be a powerful factor that can predict a poor clinical outcome, including mortality [49]. Therefore, for CKD patients with low life expectancy, strict management of weight, blood pressure, DM, etc., and low serum cholesterol and Hcy maintenance, which are known to be highly associated with long-term survival, maybe less important to improve clinical outcome, compared with the general population. Thus, the presence of reverse epidemiology may not necessarily imply that the principles of vascular pathophysiology are different in CKD patients. However, it might indicate that other superimposed factors, such as PEW and inflammation, are more important.

In conclusion, this study did not find a correlation between the Hcy level and mortality rate among the CKD group, unlike in the non-CKD group. This altered risk factor patterns may be attributed to protein-energy wasting or chronic inflammation status that is accompanied by CKD.

\title{
Abbreviations
}

\author{
Body Mass Index = BMI \\ Cardiovascular disease $=$ CVD \\ Chronic Kidney Disease $=$ CKD \\ Confidence Interval $=\mathrm{Cl}$ \\ C-reactive protein $=\mathrm{CRP}$ \\ Diabetes Mellitus $=\mathrm{DM}$ \\ Diastolic blood pressure $=$ DBP \\ End-stage renal disease $=$ ESRD \\ Hazard ratio $=\mathrm{HR}$ \\ Hyperhomocysteinemia = HHcy \\ Homocysteine $=$ Hcy
}


Methylenetetrahydrofolate Reductase $=$ MTHFR

National Center for Health Statistics $=$ NCHS

National Health and Nutrition Examination Surveys $=$ NHANES

Odd ratios $=$ ORs

Estimated Glomerular Filtration Rate = eGFR,

The National Center for Health Statistics $=$ NCHS

Protein-energy wasting $=$ NHANES

Ethics Review Board $=$ ERB

Systolic Blood Pressure $=$ SBP

Total homocysteine $=$ tHcy $)$

Urine albumin creatinine ratio $=$ UACR

\section{Declarations}

\section{Ethics approval and consent to participate}

This study protocol received approval by the National Center for Health Statistics (NCHS) Institutional Review Board of NHANES

\section{Consent for publication}

N/A

\section{Availability of data and materials}

The datasets generated during and/or analysed during the current study are available from the corresponding author on reasonable request.

Competing interests

None

Funding

None

\section{Authors' contributions}

Research idea and study design: KDY, GSK; data acquisition: JHS, HH, KDY, GSK; data analysis/interpretation: HH, JHS, GSK, KDY; supervision or mentorship: EB, JL, JPL, JSL. Each author contributed important intellectual content during manuscript drafting or revision. All authors read and approved the final manuscript.

\section{Acknowledgements}

None 


\section{References}

1. Carracedo J, Alique M, Vida C, Bodega G, Ceprian N, Morales E, Praga M, de Sequera P, Ramirez R: Mechanisms of Cardiovascular Disorders in Patients With Chronic Kidney Disease: A Process Related to Accelerated Senescence. Frontiers in cell and developmental biology2020, 8:185.

2. Weiner DE, Tighiouart H, Amin MG, Stark PC, MacLeod B, Griffith JL, Salem DN, Levey AS, Sarnak MJ: Chronic kidney disease as a risk factor for cardiovascular disease and all-cause mortality: a pooled analysis of community-based studies. Journal of the American Society of Nephrology : JASN2004, 15(5):1307-1315.

3. Said S, Hernandez GT: The link between chronic kidney disease and cardiovascular disease. Journal of nephropathology2014, 3(3):99-104.

4. Jankowski J, Floege J, Fliser D, Bohm M, Marx N: Cardiovascular Disease in Chronic Kidney Disease: Pathophysiological Insights and Therapeutic Options. Circulation2021, 143(11):1157-1172.

5. Nygård O, Nordrehaug JE, Refsum H, Ueland PM, Farstad M, Vollset SE: Plasma homocysteine levels and mortality in patients with coronary artery disease. The New England journal of medicine1997, 337(4):230-236.

6. Chambers JC, Obeid OA, Refsum H, Ueland P, Hackett D, Hooper J, Turner RM, Thompson SG, Kooner JS: Plasma homocysteine concentrations and risk of coronary heart disease in UK Indian Asian and European men. The Lancet2000, 355(9203):523-527.

7. Bostom AG, Lathrop L: Hyperhomocysteinemia in end-stage renal disease: prevalence, etiology, and potential relationship to arteriosclerotic outcomes. Kidney Int1997, 52(1):10-20.

8. Ducloux D, Klein A, Kazory A, Devillard N, Chalopin JM: Impact of malnutrition-inflammation on the association between homocysteine and mortality. Kidney Int2006, 69(2):331-335.

9. Kielstein JT, Salpeter SR, Buckley NS, Cooke JP, Fliser D: Two Cardiovascular Risk Factors in One? Homocysteine and Its Relation to Glomerular Filtration Rate. Kidney and Blood Pressure Research2008, 31(4):259-267.

10. Yang Q, Lu Y, Deng Y, Xu J, Zhang X: Homocysteine level is positively and independently associated with serum creatinine and urea nitrogen levels in old male patients with hypertension. Sci Rep2020, 10(1):18050.

11. Long Y, Nie J: Homocysteine in Renal Injury. Kidney Diseases2016, 2(2):80-87.

12. Kalantar-Zadeh K, Block G, Humphreys MH, Kopple JD: Reverse epidemiology of cardiovascular risk factors in maintenance dialysis patients. Kidney Int2003, 63(3):793-808.

13. Hwang SD, Lee JH, Jhee JH, Song JH, Kim JK, Lee SW: Impact of body mass index on survival in patients undergoing peritoneal dialysis: Analysis of data from the Insan Memorial End-Stage Renal Disease Registry of Korea (1985-2014). Kidney research and clinical practice2019, 38(2):239-249.

14. Park J: Kidney disease and obesity paradox. Kidney research and clinical practice2017, 36(1):1-2.

15. Bulbul MC, Dagel T, Afsar B, Ulusu NN, Kuwabara M, Covic A, Kanbay M: Disorders of Lipid Metabolism in Chronic Kidney Disease. Blood purification2018, 46(2):144-152.

16. Suliman ME, Stenvinkel $P$, Heimbürger $O$, Bàràny $P$, Lindholm B, Bergström J: Plasma sulfur amino acids in relation to cardiovascular disease, nutritional status, and diabetes mellitus in patients with chronic renal failure at start of dialysis therapy. American journal of kidney diseases : the official journal of the National Kidney Foundation2002, 40(3):480-488. 
17. Wrone EM, Zehnder JL, Hornberger JM, McCann LM, Coplon NS, Fortmann SP: An MTHFR variant, homocysteine, and cardiovascular comorbidity in renal disease. Kidney Int2001, 60(3):1106-1113.

18. Jamison RL, Hartigan P, Kaufman JS, Goldfarb DS, Warren SR, Guarino PD, Gaziano JM, Veterans Affairs Site I: Effect of homocysteine lowering on mortality and vascular disease in advanced chronic kidney disease and end-stage renal disease: a randomized controlled trial. Jama2007, 298(10):1163-1170.

19. Plan and operation of the Third National Health and Nutrition Examination Survey, 1988-94. Series 1: programs and collection procedures. Vital and health statistics Ser 1, Programs and collection procedures1994(32):1-407.

20. Wolffenbuttel BHR, Heiner-Fokkema MR, Green R, Gans ROB: Relationship between serum B12 concentrations and mortality: experience in NHANES. BMC Med2020, 18(1):307.

21. Go AS, Chertow GM, Fan D, McCulloch CE, Hsu CY: Chronic kidney disease and the risks of death, cardiovascular events, and hospitalization. The New England journal of medicine2004, 351(13):1296-1305.

22. Yap S, Naughten ER, Wilcken B, Wilcken DE, Boers GH: Vascular complications of severe hyperhomocysteinemia in patients with homocystinuria due to cystathionine beta-synthase deficiency: effects of homocysteine-lowering therapy. Seminars in thrombosis and hemostasis2000, 26(3):335-340.

23. Klerk M, Verhoef P, Clarke R, Blom HJ, Kok FJ, Schouten EG: MTHFR 677C $\rightarrow$ T polymorphism and risk of coronary heart disease: a meta-analysis. Jama2002, 288(16):2023-2031.

24. Zhou J, Austin RC: Contributions of hyperhomocysteinemia to atherosclerosis: Causal relationship and potential mechanisms. BioFactors (Oxford, England)2009, 35(2):120-129.

25. Hofmann MA, Lalla E, Lu Y, Gleason MR, Wolf BM, Tanji N, Ferran LJ, Jr., Kohl B, Rao V, Kisiel Wet al: Hyperhomocysteinemia enhances vascular inflammation and accelerates atherosclerosis in a murine model. The Journal of clinical investigation2001, 107(6):675-683.

26. Wald DS, Law M, Morris JK: Homocysteine and cardiovascular disease: evidence on causality from a meta-analysis. BMJ (Clinical research ed)2002, 325(7374):1202.

27. McCully KS: Vascular pathology of homocysteinemia: implications for the pathogenesis of arteriosclerosis. The American journal of pathology1969, 56(1):111-128.

28. Soinio M, Marniemi J, Laakso M, Lehto S, Rönnemaa T: Elevated plasma homocysteine level is an independent predictor of coronary heart disease events in patients with type 2 diabetes mellitus. Annals of internal medicine2004, 140(2):94-100.

29. Lawrence de Koning AB, Werstuck GH, Zhou J, Austin RC: Hyperhomocysteinemia and its role in the development of atherosclerosis. Clinical biochemistry2003, 36(6):431-441.

30. Yap S, Boers GH, Wilcken B, Wilcken DE, Brenton DP, Lee PJ, Walter JH, Howard PM, Naughten ER: Vascular outcome in patients with homocystinuria due to cystathionine beta-synthase deficiency treated chronically: a multicenter observational study. Arteriosclerosis, thrombosis, and vascular biology2001, 21(12):2080-2085.

31. Pan Y, Guo LL, Cai LL, Zhu XJ, Shu JL, Liu XL, Jin HM: Homocysteine-lowering therapy does not lead to reduction in cardiovascular outcomes in chronic kidney disease patients: a meta-analysis of randomised, controlled trials. The British journal of nutrition2012, 108(3):400-407. 
32. Nigwekar SU, Kang A, Zoungas S, Cass A, Gallagher MP, Kulshrestha S, Navaneethan SD, Perkovic V, Strippoli GF, Jardine MJ: Interventions for lowering plasma homocysteine levels in dialysis patients. The Cochrane database of systematic reviews2016(5):Cd004683.

33. Moon H, Ko HJ, Kim AS: Hyperhomocysteinemia Concurrent with Metabolic Syndrome Is Independently Associated with Chronic Kidney Disease among Community-Dwelling Adults in an Urban Korean Population. Int J Environ Res Public Health2020, 17(18).

34. Suliman M, Stenvinkel P, Qureshi AR, Kalantar-Zadeh K, Bárány P, Heimbürger O, Vonesh EF, Lindholm B: The reverse epidemiology of plasma total homocysteine as a mortality risk factor is related to the impact of wasting and inflammation. Nephrology, dialysis, transplantation : official publication of the European Dialysis and Transplant Association - European Renal Association2007, 22(1):209-217.

35. Suliman ME, Lindholm B, Barany P, Qureshi AR, Stenvinkel P: Homocysteine-lowering is not a primary target for cardiovascular disease prevention in chronic kidney disease patients. Seminars in dialysis2007, 20(6):523-529.

36. Heinz J, Kropf S, Luley C, Dierkes J: Homocysteine as a risk factor for cardiovascular disease in patients treated by dialysis: a meta-analysis. American journal of kidney diseases : the official journal of the National Kidney Foundation2009, 54(3):478-489.

37. de Koning L, Hu FB: Homocysteine lowering in end-stage renal disease: is there any cardiovascular benefit? Circulation2010, 121(12):1379-1381.

38. Sirrs S, Duncan L, Djurdjev O, Nussbaumer G, Ganz G, Frohlich J, Levin A: Homocyst(e)ine and vascular access complications in haemodialysis patients: insights into a complex metabolic relationship. Nephrology, dialysis, transplantation : official publication of the European Dialysis and Transplant Association - European Renal Association1999, 14(3):738-743.

39. Kalantar-Zadeh K, Block G, Humphreys MH, McAllister CJ, Kopple JD: A low, rather than a high, total plasma homocysteine is an indicator of poor outcome in hemodialysis patients. Journal of the American Society of Nephrology : JASN2004, 15(2):442-453.

40. van Guldener C, Stam F, Stehouwer CD: Hyperhomocysteinaemia in chronic kidney disease: focus on transmethylation. Clinical chemistry and laboratory medicine2005, 43(10):1026-1031.

41. Oishi K, Nagake Y, Yamasaki H, Fukuda S, Ichikawa H, Ota K, Makino H: The significance of serum homocysteine levels in diabetic patients on haemodialysis. Nephrology, dialysis, transplantation : official publication of the European Dialysis and Transplant Association - European Renal Association2000, 15(6):851-855.

42. Suliman ME, Stenvinkel P, Qureshi AR, Bárány P, Heimburger O, Anderstam B, Alvestrand A, Lindholm B:

Hyperhomocysteinemia in relation to plasma free amino acids, biomarkers of inflammation and mortality in patients with chronic kidney disease starting dialysis therapy. American journal of kidney diseases : the official journal of the National Kidney Foundation2004, 44(3):455-465.

43. Qureshi AR, Alvestrand A, Divino-Filho JC, Gutierrez A, Heimbürger O, Lindholm B, Bergström J: Inflammation, malnutrition, and cardiac disease as predictors of mortality in hemodialysis patients. Journal of the American Society of Nephrology : JASN2002, 13 Suppl 1:S28-36.

44. Kalantar-Zadeh K, Ikizler TA, Block G, Avram MM, Kopple JD: Malnutrition-inflammation complex syndrome in dialysis patients: causes and consequences. American journal of kidney diseases : the official journal of the National Kidney

Foundation2003, 42(5):864-881.

Page 10/18 
45. Grabowski DC, Ellis JE: High body mass index does not predict mortality in older people: analysis of the Longitudinal Study of Aging. Journal of the American Geriatrics Society2001, 49(7):968-979.

46. Friedman EA: Selection bias impacts outcome reports of uremia therapy. American journal of kidney diseases : the official journal of the National Kidney Foundation2000, 36(1):208-210.

47. Klag MJ, Ford DE, Mead LA, He J, Whelton PK, Liang KY, Levine DM: Serum cholesterol in young men and subsequent cardiovascular disease. The New England journal of medicine1993, 328(5):313-318.

48. Cui Y, Blumenthal RS, Flaws JA, Whiteman MK, Langenberg P, Bachorik PS, Bush TL: Non-high-density lipoprotein cholesterol level as a predictor of cardiovascular disease mortality. Archives of internal medicine2001, 161(11):1413-1419.

49. Collins S, Myatt M: Short-term prognosis in severe adult and adolescent malnutrition during famine: use of a simple prognostic model based on counting clinical signs. Jama2000, 284(5):621-626.

\section{Tables}

Table 1. Baseline characteristics of the study population according CKD

BMI, body mass index; DBP, diastolic blood pressure; ESC, European Society of Cardiology; GFR, glomerular filtration ratio; IDH, isolated diastolic hypertension; ISH, isolated systolic hypertension; NICE, National Institute for Health and Care Excellence; SBP, systolic blood pressure; and SDH, systolic and diastolic hypertension.

Table 2. Hazard ratios of all-cause mortality according to homocysteine level (quartile)

\begin{tabular}{|c|c|c|c|c|c|c|c|c|c|}
\hline & \multicolumn{3}{|c|}{ All $(n=9895)$} & \multicolumn{3}{|c|}{ CKD $(n=1025)$} & \multicolumn{3}{|c|}{ Non-CKD $(n=8870)$} \\
\hline & $\mathrm{HR}$ & $95 \% \mathrm{Cl}$ & $P$ & $\mathrm{HR}$ & $95 \% \mathrm{Cl}$ & $P$ & $\mathrm{HR}$ & $95 \% \mathrm{Cl}$ & $P$ \\
\hline & \multicolumn{9}{|c|}{ All-cause mortality } \\
\hline \multicolumn{10}{|c|}{ Model 1} \\
\hline Q2 & 2.073 & $1.633-2.632$ & $<0.001$ & 0.833 & $0.293-2.365$ & 0.731 & 2.071 & $1.261-2.646$ & $<0.001$ \\
\hline Q3 & 3.602 & $2.885-4.498$ & $<0.001$ & 1.155 & $0.467-2.857$ & 0.756 & 3.176 & 2.517-4.009 & $<0.001$ \\
\hline Q4 & 11.361 & $9.244-13.961$ & $<0.001$ & 2.183 & $0.905-5.269$ & 0.082 & 7.608 & $6.097-9.493$ & $<0.001$ \\
\hline \multicolumn{10}{|c|}{ Model 2} \\
\hline Q2 & 1.470 & $1.155-1.872$ & 0.002 & 0.767 & $0.270-2.178$ & 0.618 & 1.434 & $1.118-1.840$ & 0.005 \\
\hline Q3 & 1.857 & $1.474-2.339$ & $<0.001$ & 0.960 & $0.388-2.379$ & 0.930 & 1.657 & $1.298-2.116$ & $<0.001$ \\
\hline Q4 & 3.841 & $3.073-4.800$ & $<0.001$ & 1.706 & $0.706-4.127$ & 0.236 & 2.962 & $2.328-3.768$ & $<0.001$ \\
\hline \multicolumn{10}{|c|}{ Model 3} \\
\hline Q2 & 1.751 & $1.348-2.274$ & $<0.001$ & 0.882 & $0.280-2.775$ & 0.830 & 1.707 & $1.301-2.240$ & $<0.001$ \\
\hline Q3 & 2.220 & $1.726-2.855$ & $<0.001$ & 1.231 & $0.449-3.373$ & 0.687 & 1.992 & $1.523-2.604$ & $<0.001$ \\
\hline Q4 & 3.776 & $2.952-4.830$ & $<0.001$ & 1.931 & $0.720-5.182$ & 0.191 & 3.016 & 2.308-3.941 & $<0.001$ \\
\hline
\end{tabular}

CKD, chronic kidney disease; HR, hazard ratio

Model 1: crude 


\begin{tabular}{|c|c|c|c|c|c|}
\hline Variables & $\begin{array}{l}\text { Total } \\
(\mathrm{N}=9,895)\end{array}$ & $\begin{array}{l}\text { CKD } \\
(\mathrm{N}=1,025)\end{array}$ & $\begin{array}{l}\text { Non-CKD } \\
(\mathrm{N}=\mathbf{8 , 8 7 0})\end{array}$ & $P$ & $\begin{array}{l}\text { Model 2: adjusted for age } \\
\text { over 65, gender }\end{array}$ \\
\hline Age (years) & $47 \pm 20$ & $73 \pm 11$ & $44 \pm 18$ & $<0.001$ & Model 3: adjusted for age \\
\hline Men, \% & $4789(48.4)$ & $487(47.5)$ & $4302(48.5)$ & 0.553 & $\begin{array}{l}\text { over 65, gender, serum } \\
\text { albumin, urine albumin }\end{array}$ \\
\hline Race/ethnicity, \% & & & & $<0.001$ & creatinine ratio, smoking \\
\hline Non-Hispanic white & $5005(50.6)$ & $640(62.4)$ & $4365(49.2)$ & & status, body mass index, \\
\hline Non-Hispanic black & $2145(21.7)$ & $253(24.7)$ & $1892(21.3)$ & & hypertension and diabetes \\
\hline Other-Hispanic & $309(3.1)$ & $14(1.4)$ & $295(3.3)$ & & mellitus \\
\hline Mexican-American & $2033(20.5)$ & $86(8.4)$ & $1947(22.0)$ & & CKD was defined as \\
\hline Other & $403(4.1)$ & $32(3.1)$ & $371(4.2)$ & & estimated GFR $<60$ \\
\hline Education level, \% & & & & $<0.001$ & $\begin{array}{l}\mathrm{ml} / \mathrm{min} / 1.73 \mathrm{~m}^{2}, \text { Reference } \\
\text { was Quartile } 1 \text { in model 1, 2, }\end{array}$ \\
\hline$<12$ years & $2615(28.0)$ & $378(36.9)$ & $2237(27.0)$ & & 3 \\
\hline $12-15$ years & 2277 (24.4) & $272(26.6)$ & $2005(24.1)$ & & Table 3. Odds ratios of \\
\hline$\geq 16$ years & $2615(28.0)$ & $212(20.7)$ & $2403(28.9)$ & & chronic kidney disease using \\
\hline $\mathrm{BMI}\left(\mathrm{kg} / \mathrm{m}^{2}\right)$ & $28.5 \pm 6.5$ & $29.0 \pm 6.2$ & $28.4 \pm 6.6$ & 0.012 & logistic regression \\
\hline $\mathrm{SBP}(\mathrm{mmHg})$ & $125 \pm 21$ & $142 \pm 26$ & $123 \pm 19$ & $<0.001$ & \\
\hline $\mathrm{DBP}(\mathrm{mmHg})$ & $69 \pm 14$ & $66 \pm 19$ & $70 \pm 13$ & $<0.001$ & \\
\hline Smoking status, $\%$ & & & & $<0.001$ & \\
\hline Never & $4783(51.3)$ & $503(49.1)$ & $4280(51.5)$ & & \\
\hline Ex-smoker & $2457(26.3)$ & $408(39.8)$ & $2049(24.7)$ & & \\
\hline Current & $2081(22.3)$ & $112(10.9)$ & $1969(23.7)$ & & \\
\hline Albumin $(\mathrm{g} / \mathrm{dL})$ & $4.2 \pm 0.4$ & $4.0 \pm 0.4$ & $4.2 \pm 0.4$ & $<0.001$ & \\
\hline \multicolumn{5}{|l|}{ Cholesterol (mg/dL) } & \\
\hline Uric acid $(\mathrm{mg} / \mathrm{dL})$ & $5.4 \pm 1.4$ & $6.5 \pm 1.6$ & $5.2 \pm 1.4$ & $<0.001$ & \\
\hline Estimated GFR $\left(\mathrm{mL} / \mathrm{min} / 1.73 \mathrm{~m}^{2}\right)$ & $92 \pm 25$ & $46 \pm 12$ & $98 \pm 20$ & $<0.001$ & \\
\hline Homocysteine (umol/L) & $8.8 \pm 4.7$ & $13.5 \pm 5.1$ & $8.3 \pm 4.3$ & $<0.001$ & \\
\hline Albumin creatinine ratio $(\mathrm{mg} / \mathrm{g})$ & $43.1 \pm 341.4$ & $215.5 \pm 926.5$ & $24.1 \pm 175.8$ & $<0.001$ & \\
\hline Hypertension, \% & 3771 (38.1) & $810(79.0)$ & 2961 (33.4) & $<0.001$ & \\
\hline Diabetes, \% & 1117 (11.3) & $296(28.9)$ & $821(9.3)$ & $<0.001$ & \\
\hline
\end{tabular}




\begin{tabular}{|lllll|}
\hline Variables & Univariate & & Multivariate & \\
\hline & OR (95\% Cl) & $\boldsymbol{p}$ & OR $(95 \% \mathrm{Cl})$ & $\boldsymbol{p}$ \\
\hline Age & $1.114(1.107-1.121)$ & $<0.001$ & $1.096(1.083-1.109)$ & $<0.001$ \\
\hline Gender (male) & $0.961(0.844-1.094)$ & 0.549 & $0.460(0.350-0.605)$ & $<0.001$ \\
\hline Hypertension & $7.518(6.428-8.794)$ & $<0.001$ & $1.699(1.259-2.291)$ & 0.001 \\
\hline Diabetes mellitus & $3.981(3.416-4.639)$ & $<0.001$ & $1.824(1.264-2.633)$ & 0.001 \\
\hline Obesity (BMl>30) & $1.343(1.135-1.589)$ & $<0.001$ & $0.942(0.663-1.339)$ & 0.739 \\
\hline Uric acid & $1.807(1.724-1.893)$ & $<0.001$ & $1.583(1.435-1.746)$ & $<0.001$ \\
\hline Fasting glucose & $1.006(1.004-1.008)$ & $<0.001$ & $0.997(0.992-1.001)$ & 0.152 \\
\hline HCY (Ref Q1) & & & & \\
\hline Q2 & $2.797(1.515-5.164)$ & 0.001 & $0.588(0.229-1.506)$ & 0.268 \\
\hline Q3 & $13.85(8.017-23.925)$ & $<0.001$ & $2.439(1.074-5.539)$ & 0.033 \\
\hline Q4 & $81.94(48.132-139.5)$ & $<0.001$ & $7.518(3.342-16.911)$ & $<0.001$ \\
\hline Current smoking & $0.395(0.323-0.484)$ & $<0.001$ & $0.877(0.592-1.300)$ & 0.514 \\
\hline
\end{tabular}

adjusted for age, gender, smoking status, body mass index, hypertension and diabetes mellitus, serum glucose, uric acid and $\mathrm{HCY}$ quartile.

CKD was defined as estimated GFR $<60 \mathrm{ml} / \mathrm{min} / 1.73 \mathrm{~m}^{2}$

Table 4. Baseline characteristics of the study population according CKD before and after propensity score matching. 


\begin{tabular}{|c|c|c|c|c|c|c|c|c|}
\hline Variables & $\begin{array}{c}\text { No CKD } \\
(\mathrm{N}= \\
8870)\end{array}$ & $\begin{array}{l}\text { CKD } \\
(N=1025)\end{array}$ & $P$ & SD & $\begin{array}{l}\text { No CKD } \\
(\mathrm{N} \\
=2015)\end{array}$ & $\begin{array}{l}\text { CKD } \\
(\mathrm{N}=741)\end{array}$ & $P$ & SD \\
\hline Age (years) & $44 \pm 18$ & $73 \pm 11$ & $<0.001$ & 2.439 & $65 \pm 15$ & $71 \pm 12$ & $<0.001$ & 0.157 \\
\hline $\begin{array}{l}\text { Age over } 65 \\
\text { years, } \%\end{array}$ & $\begin{array}{l}1405 \\
(15.8)\end{array}$ & $806(78.6)$ & $<0.001$ & 1.504 & $\begin{array}{l}1116 \\
(55.4)\end{array}$ & $537(72.5)$ & $<0.001$ & 0.066 \\
\hline Men, \% & $\begin{array}{l}4302 \\
(48.5)\end{array}$ & 487 (47.5) & 0.553 & 0.023 & $\begin{array}{l}1031 \\
(51.2)\end{array}$ & 367 (49.5) & 0.465 & 0.000 \\
\hline Race/ethnicity, \% & & & $<0.001$ & 0.373 & & & 0.059 & 0.000 \\
\hline $\begin{array}{l}\text { Non-Hispanic } \\
\text { white }\end{array}$ & $\begin{array}{l}4365 \\
(49.2)\end{array}$ & $640(62.4)$ & & & $\begin{array}{l}1182 \\
(58.7)\end{array}$ & $460(62.1)$ & & \\
\hline $\begin{array}{l}\text { Non-Hispanic } \\
\text { black }\end{array}$ & $\begin{array}{l}1892 \\
(21.3)\end{array}$ & $253(24.7)$ & & & $425(21.1)$ & $173(23.3)$ & & \\
\hline Other-Hispanic & 295 (3.3) & $14(1.4)$ & & & $40(2.0)$ & $12(1.6)$ & & \\
\hline $\begin{array}{l}\text { Mexican- } \\
\text { American }\end{array}$ & $\begin{array}{l}1947 \\
(22.0)\end{array}$ & $86(8.4)$ & & & $275(13.6)$ & $72(9.7)$ & & \\
\hline Other & $371(4.2)$ & $32(3.1)$ & & & $93(4.6)$ & $24(3.2)$ & & \\
\hline Education level, \% & & & $<0.001$ & & & & 0.116 & \\
\hline$<12$ years & $\begin{array}{l}2005 \\
(22.6)\end{array}$ & $272(26.5)$ & & & $509(25.3)$ & $202(27.1)$ & & \\
\hline $12-15$ years & $\begin{array}{l}2403 \\
(27.1)\end{array}$ & $212(20.7)$ & & & $523(26.0)$ & $153(20.6)$ & & \\
\hline$\geq 16$ years & $\begin{array}{l}1652 \\
(18.6)\end{array}$ & $157(15.3)$ & & & $350(17.4)$ & $129(17.4)$ & & \\
\hline $\mathrm{BMI}\left(\mathrm{kg} / \mathrm{m}^{2}\right)$ & $28.4 \pm 6.6$ & $29.0 \pm 6.2$ & 0.012 & 0.056 & $29.2 \pm 6.4$ & $28.8 \pm 6.1$ & 0.116 & -0.031 \\
\hline Weight (kg) & $80.4 \pm 20.7$ & $79.5 \pm 19.7$ & 0.191 & -0.068 & $82.0 \pm 20.5$ & $79.8 \pm 19.7$ & 0.013 & -0.036 \\
\hline $\mathrm{SBP}(\mathrm{mmHg})$ & $123 \pm 19$ & $142 \pm 26$ & $<0.001$ & & $134 \pm 23$ & $141 \pm 25$ & $<0.001$ & \\
\hline $\mathrm{DBP}(\mathrm{mmHg})$ & $70 \pm 13$ & $66 \pm 19$ & $<0.001$ & & $70 \pm 15$ & $67 \pm 19$ & $<0.001$ & \\
\hline $\begin{array}{l}\text { Smoking status, } \\
\%\end{array}$ & & & $<0.001$ & 0.156 & & & 0.313 & -0.012 \\
\hline Never & $\begin{array}{l}4280 \\
(51.5)\end{array}$ & $503(49.1)$ & & & $932(46.3)$ & $351(47.4)$ & & \\
\hline Ex-smoker & $\begin{array}{l}2049 \\
(24.7)\end{array}$ & $408(39.8)$ & & & 788 (39.1) & $296(39.9)$ & & \\
\hline Current & $\begin{array}{l}1969 \\
(23.7)\end{array}$ & $112(10.9)$ & & & $295(14.6)$ & $94(12.7)$ & & \\
\hline Albumin (g/dL) & $4.2 \pm 0.4$ & $4.0 \pm 0.4$ & $<0.001$ & -0.301 & $4.1 \pm 0.3$ & $4.1 \pm 0.4$ & 0.017 & -0.005 \\
\hline Glucose (mg/dL) & $97.1 \pm 33.4$ & $110.3 \pm 41.2$ & $<0.001$ & & $107.3 \pm 39.9$ & $108.2 \pm 41.8$ & 0.608 & \\
\hline Uric acid (mg/dL) & $5.2 \pm 1.4$ & $6.5 \pm 1.6$ & $<0.001$ & 0.798 & $5.8 \pm 1.4$ & $6.1 \pm 1.5$ & $<0.001$ & 0.050 \\
\hline $\begin{array}{l}\text { Estimated GFR } \\
\left(\mathrm{mL} / \mathrm{min} / 1.73 \mathrm{~m}^{2}\right)\end{array}$ & $98 \pm 20$ & $46 \pm 12$ & $<0.001$ & & $81 \pm 15$ & $48 \pm 12$ & $<0.001$ & \\
\hline Albumin & $24.1 \pm 175.8$ & $215.5 \pm 926.5$ & $\begin{array}{r}<0.001 \\
\text { Page } 1\end{array}$ & & $42.3 \pm 161.3$ & $221.8 \pm 981.0$ & $<0.001$ & \\
\hline
\end{tabular}


creatinine ratio

(mg/g)

\begin{tabular}{|lllllllll|}
\hline Diabetes, \% & $821(9.3)$ & $296(28.9)$ & $<0.001$ & 0.422 & $430(21.3)$ & $184(24.8)$ & 0.056 & -0.014 \\
\hline Hypertension, \% & $\begin{array}{l}2961 \\
(33.4)\end{array}$ & $810(79.0)$ & $<0.001$ & 1.093 & $\begin{array}{l}1356 \\
(67.3)\end{array}$ & $565(76.2)$ & $<0.001$ & 0.033 \\
$\begin{array}{l}\text { Homocystein } \\
\text { (umol/L) }\end{array}$ & $8.3 \pm 4.3$ & $13.5 \pm 5.1$ & $<0.001$ & & $9.8 \pm 4.5$ & $13.1 \pm 5.2$ & $<0.001$ & \\
\hline
\end{tabular}

BMI, body mass index; DBP, diastolic blood pressure; ESC, European Society of Cardiology; GFR, glomerular filtration ratio; IDH, isolated diastolic hypertension; ISH, isolated systolic hypertension; NICE, National Institute for Health and Care Excellence; SBP, systolic blood pressure; and SDH, systolic and diastolic hypertension.

Table 5. Hazard ratios of all-cause mortality according to homocysteine level (quartile) after PSM

\begin{tabular}{|c|c|c|c|c|c|c|c|c|c|}
\hline & \multicolumn{3}{|c|}{ All $(n=2756)$} & \multicolumn{3}{|c|}{ CKD $(n=741)$} & \multicolumn{3}{|c|}{ Non-CKD $(n=2015)$} \\
\hline & $\mathrm{HR}$ & $95 \% \mathrm{Cl}$ & $P$ & $\mathrm{HR}$ & $95 \% \mathrm{Cl}$ & $P$ & $\mathrm{HR}$ & $95 \% \mathrm{Cl}$ & $P$ \\
\hline & \multicolumn{9}{|c|}{ All-cause mortality } \\
\hline \multicolumn{10}{|c|}{ Model 1} \\
\hline Q2 & 1.800 & $1.159-2.796$ & 0.009 & 0.568 & $0.189-1.736$ & 0.321 & 2.099 & $1.292-3.412$ & 0.003 \\
\hline Q3 & 2.599 & $1.720-3.927$ & $<0.001$ & 0.989 & $0.396-2.472$ & 0.982 & 2.805 & $1.766-4.455$ & $<0.001$ \\
\hline Q4 & 5.013 & $3.361-7.478$ & $<0.001$ & 1.646 & $0.680-3.982$ & 0.269 & 4.975 & $3.166-7.820$ & $<0.001$ \\
\hline \multicolumn{10}{|c|}{ Model 2} \\
\hline Q2 & 1.442 & $0.928-2.241$ & 0.104 & 0.530 & $0.173-1.622$ & 0.266 & 1.622 & $0.997-2.639$ & 0.051 \\
\hline Q3 & 1.821 & $1.202-2.759$ & 0.005 & 0.830 & $0.332-2.077$ & 0.691 & 1.875 & $1.176-2.990$ & 0.008 \\
\hline Q4 & 3.128 & $2.087-4.688$ & $<0.001$ & 1.296 & $0.534-3.146$ & 0.566 & 2.961 & $1.872-4.685$ & $<0.001$ \\
\hline \multicolumn{10}{|c|}{ Model 3} \\
\hline Q2 & 1.875 & $1.166-3.014$ & 0.010 & 0.592 & $1.173-2.028$ & 0.404 & 2.195 & $1.299-3.709$ & 0.003 \\
\hline Q3 & 2.402 & $1.530-3.773$ & $<0.001$ & 1.050 & $0.380-2.904$ & 0.924 & 2.607 & $1.570-4.332$ & $<0.001$ \\
\hline Q4 & 3.674 & $2.360-5.719$ & $<0.001$ & 1.490 & $0.553-4.017$ & 0.430 & 3.720 & $2.254-6.139$ & $<0.001$ \\
\hline
\end{tabular}

CKD, chronic kidney disease; HR, hazard ratio

Model 1: crude

Model 2: adjusted for age over 65 , gender

Model 3: adjusted for age over 65, gender, serum albumin, urine albumin creatinine ratio, smoking status, body mass index, concurrent history of hypertension and diabetes mellitus

CKD was defined as estimated GFR $<60 \mathrm{ml} / \mathrm{min} / 1.73 \mathrm{~m}^{2}$

Reference was Quartile 1 in model 1, 2, 3

\section{Figures}




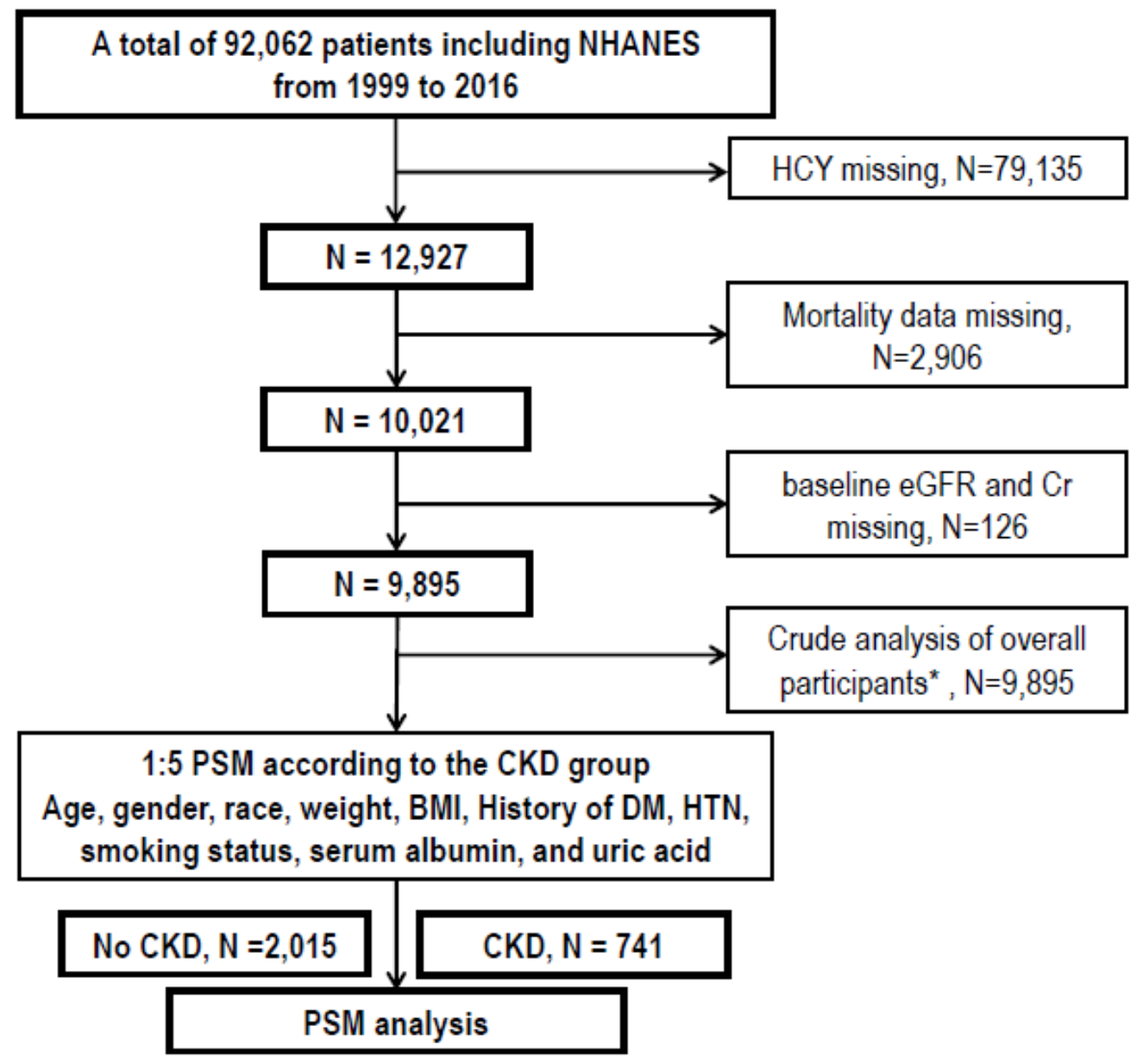

Figure 1

Study flow chart 
(A)

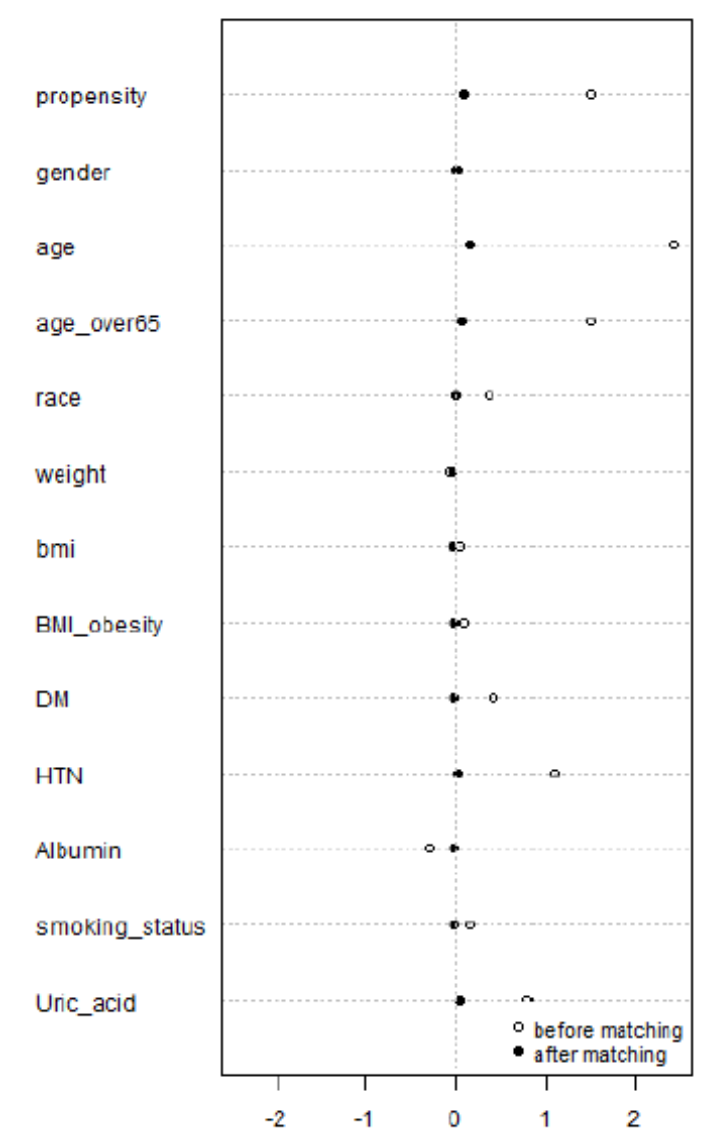

(B)
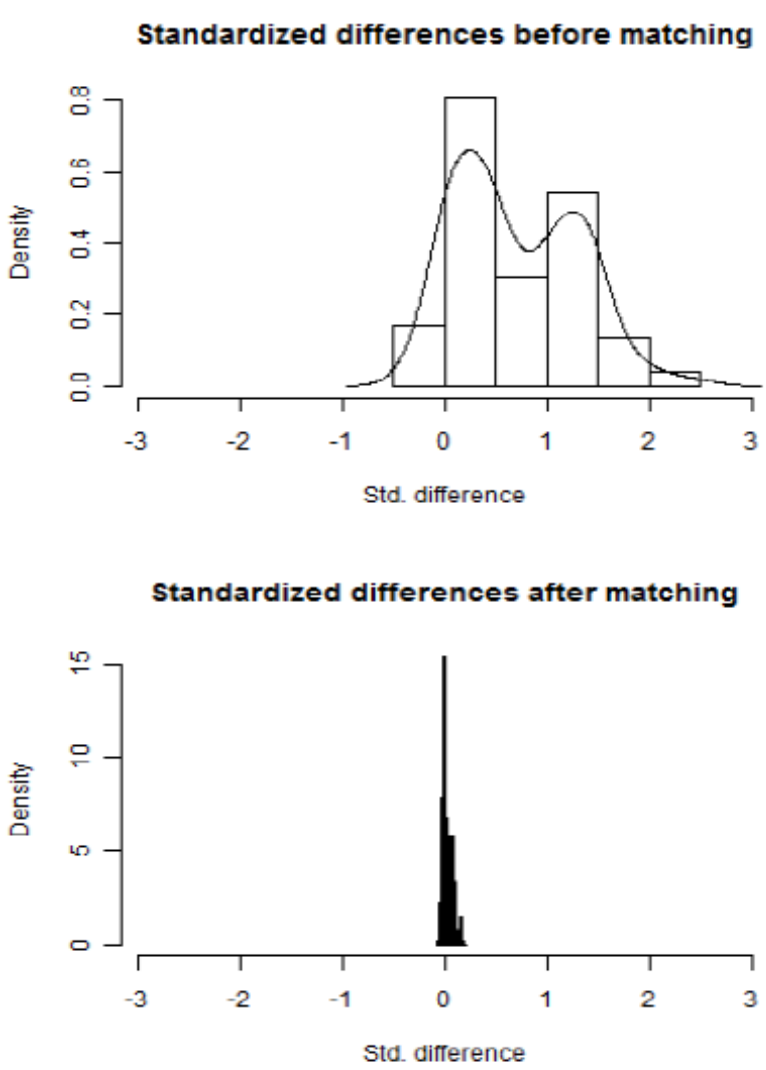

Figure 2

Standardized difference (SD) before and after propensity-score matching (A) Change of SD value for before and after propensity-score matching by variables (B) Distribution of SD for before and after propensity-score matching

(A)

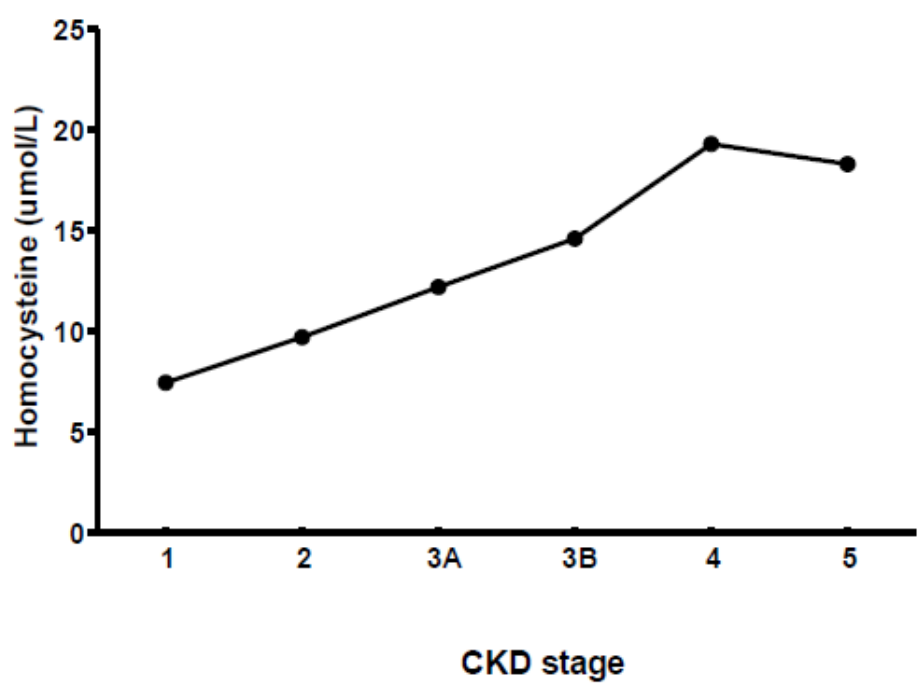

(B)

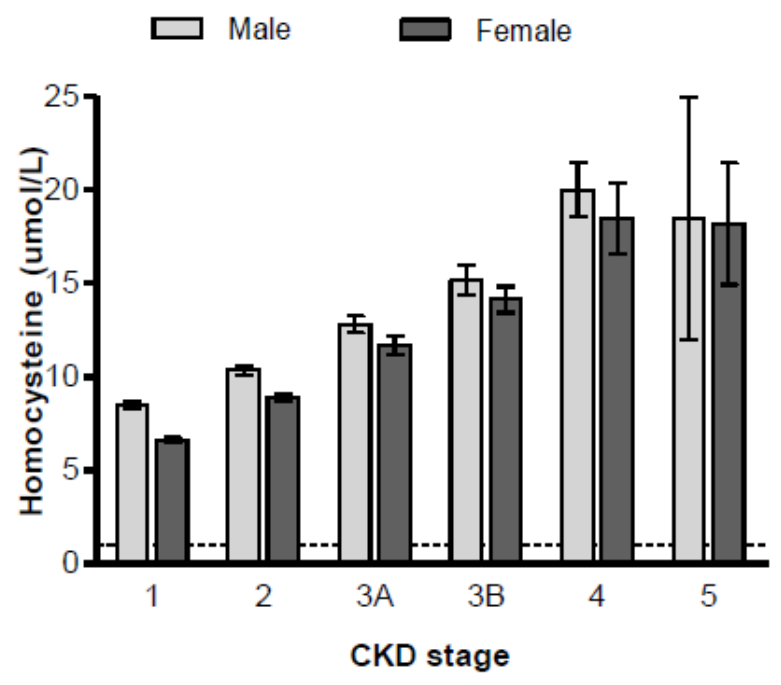

Figure 3 
Serum levels of homocysteine according to CKD stage (A) Levels of Homocysteine according to CKD stage by GFR grade (B) Levels of Homocysteine according to CKD stage by gender

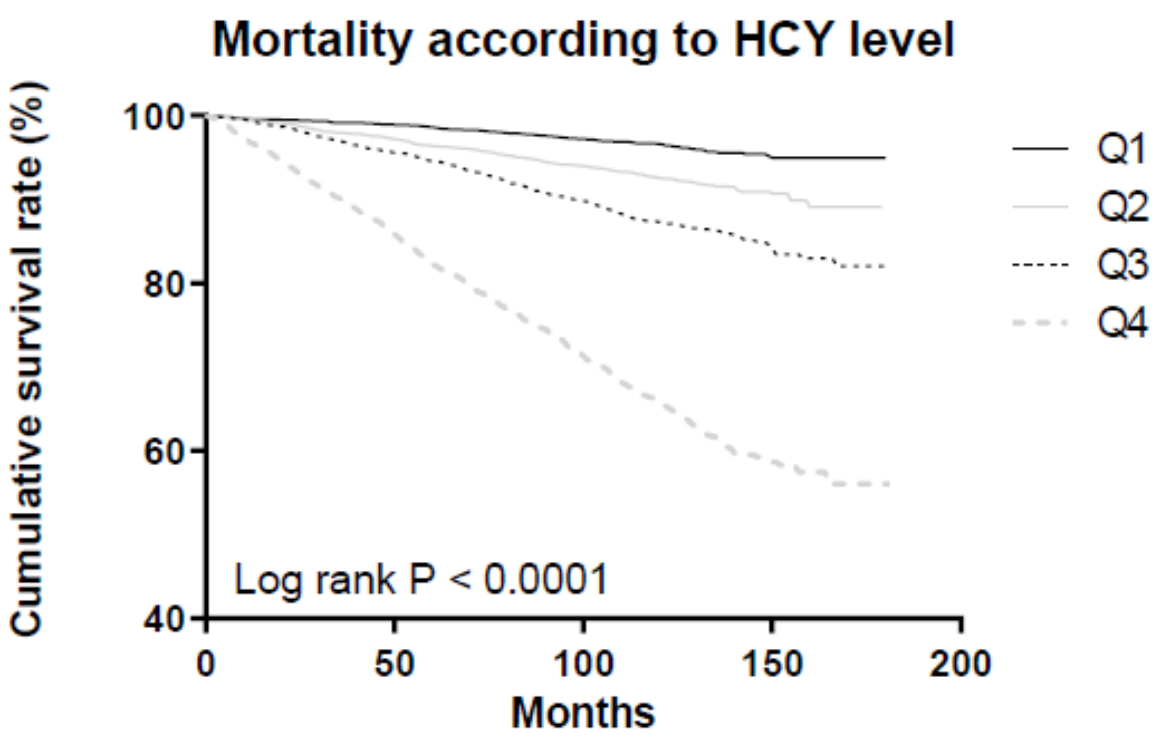

Figure 4

Comparison of the cumulative survival rate between the homocysteine quartile group 